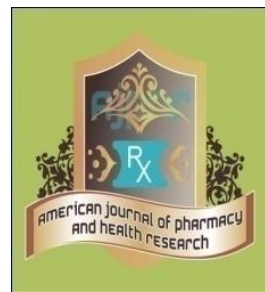

\title{
Design, Characterization and Evaluation of Quick Dissolving Matrix BARETab® ODT Tablet In Ondansetron Formulation
}

\author{
Monika Tomar ${ }^{1}$, Amit Raj Sinha ${ }^{2 *}$ \\ 1. Sigachi Industries Limited, Dahej SEZ, Bharuch, Gujarat, India. \\ 2. Sigachi Industries Limited, 4th Floor, Kalayan's Tulsiram Chambers, Madinaguda, \\ Hyderabad, Telangana (India)
}

\begin{abstract}
The oral dissolving tablets is defined as one, which has drug in it and when placed on tongue dissolves completely within a limited span of time, without additional requirement of water. Drug is released, dispersed in the saliva and swallowed and subsequently absorbed in the gastrointestinal tract (GIT). To achieve quick disintegration in oral solid dosage forms, it's important to have high porosity in the tablets. This allows faster penetration of water and thus accelerates the disintegration. Oral dissolving tablets are the preferred means for patients with oral disorders and patients with dysphagia. It could also be friendly, with geriatric, pediatric and mentally challenged people. Oral dissolving tablet formulation are made by many techniques but in this study, we have made BARETab ${ }^{\circledR}$ ODT quick dissolving matrix using spray drier, characterized by Fourier-transform infrared spectroscopy and melting point, morphology studied by scanning electron microscope, evaluation done with physicochemical test such as bulk density, flowability, average particle size distribution, compressibility index, water content and residue on ignition. Ondansetron oral dissolving tablet was thereafter made using with BARETab $^{\circledR}$ ODT quick dissolving matrix. Ondansetron oral dissolving tablet was evaluated by in-vitro testing such as physical evaluation, weight uniformity, hardness, friability, disintegration and drug released profile. BARETab ${ }^{\circledR}$ ODT quick dissolving matrix have very good morphology, every particle contains binder, filler, glidant, sweetener and super disintegrant. It has outstanding physiochemical properties which helped to deliver good quality Ondansetron tablet. It has less friability, satisfactory hardness and quick disintegration time.
\end{abstract}

Keywords: Orally Disintegrating Tablets, Fourier-transform infrared spectroscopy, melting point, Scanning electron microscopic characteristics, In-Vitro Disintegration Time 


\section{INTRODUCTION}

The oral route of administration is most widely and favourable route of drug delivery system because of its convenience of self-administration, compactness ${ }^{1}$. Oral dosages forms are easy to manufacture and convenient in handling. However, the most evident drawback of the oral dosage forms like tablets and capsules is difficulty in swallowing ${ }^{2}$. It is an estimation, approximately $50 \%$ of the population is affected by this problem worldwide, leading to patient's incompliance particularly in case of pediatric and geriatric patients, but it also applies to people who are ill in bed and to those active working patients who are busy or traveling, especially those who have no access to water ${ }^{3}$. The problem can be resolved by the creation of Orally Disintegrating Tablets (ODTs). It is also known as quick dissolving tablet, fast dissolving tablet ${ }^{4}$. ODTs rapidly disintegrate in the mouth without chewing upon oral administration and without the need for water, unlike other drug delivery systems and conventional oral solid immediate-release dosage form. It has significant impact on the patient compliance ${ }^{5}$. Orally disintegrating tablets are appreciated by a significant segment of populations particularly who have difficulty in swallowing ${ }^{6}$. It has been reported common among all age groups and more specific with pediatric, geriatric population along with institutionalized patients, psychiatric patients and patients with nausea, vomiting, and motion sickness complications. ODTs with good taste and flavour increase the acceptability of bitter drugs by various groups of population ${ }^{7}$.

Formulation scientist and tablet manufacturers faced some critical problems during ODT manufacturing such as

\section{Dispersed in mouth within seconds:}

This is one among the most critical points in an ODT formulation. It directly co-relates to the Tablet strength and is a function of the tableting force. What is essential is a delicate balance between the Tablet hardness and its disintegrating time ${ }^{8,9}$.

\section{Be portable, without concern for any friability:}

This is a factor of the tablet hardness and is critical in ensuring that the dosage quantity remains $\operatorname{intact}^{10.11}$.

\section{Cost Effective, both at production level and at administration level:}

ODT should be formulated with technologies, which are acceptable in terms of cost and scalability. No use of having a superior technology, which cannot be put to good patient use, due to higher $\operatorname{costs}^{12}$.

\section{Good mouth feel and taste masking:}


Most drugs are bitter in taste. Taste masking and good mouth feel become essential traits in an ODT to be easily accepted among the kids and elders alike. Many techniques are used in taste masking like formulation of pallets by extrusion, mass extrusion or spheronization, polymer used in coating of drug, spray drying the drug in a dispersion of polymer and microencapsulation of drug etc ${ }^{13}$.

\section{No leftover residue in mouth after administration:}

The ODT should generate small to very small particles in the mouth and these small particles flow into the GI Tract, thus leaving no residue in the mouth. The good mouth feel is enhanced by flavour and small particles. Many orally disintegrating tablet formulations are available in the market $^{14}$.

Numerous technologies have been developed for preparation of ODT drug delivery system like as freeze and spray drying, moulding, phase transition process, melt granulation, sublimation, mass extrusion, cotton candy process and direct compression. Among the above, spray drying and direct compression are the most common and cost-effective techniques used to make ODT ${ }^{15}$. Whereas spray drying is the fastest way to dry a solution to powder form, with very high porosity. The high porosity is developed due to rapid drying in a co-current or counter -current air flow ${ }^{16}$. Spray drying is based on particular support matrix, which is formed by co processing an aqueous solution containing the product and the medium. The ODT made by this technology disintegrate within a time frame of 20-30 seconds ${ }^{17}$. USFDA guidelines suggest 30 seconds as the disintegration time (in-vitro), whereas European Pharmacopoeia indicates disintegration time of less than 3 minutes Spray drying powder is commonly used for direct compression formulation, because of its superior flowability. Direct Compression is the most common and economic form of making the ODT formulations ${ }^{18,19}$.

The present study main aim is to design, characterize and evaluate ODT quick dissolving matrix. Characterization study has been done by FTIR and melting point test and evaluation study done by Morphology and physicochemical test. After that Ondansetron direct compressible ODT tablet formulation were made using BARETab ${ }^{\circledR}$ ODT quick dissolving matrix and evaluated invitro parameters like as tablet weight uniformity, hardness, friability, in-vitro disintegration time and Ondansetron released profile by dissolution test ${ }^{20}$.

MATERIALS AND METHOD:

\section{Material:}


$\mathrm{HiCel}^{\mathrm{TM}}$ filler, binder, glidant and HiLose ${ }^{\mathrm{TM}}$ Super disintegrant manufactured at Sigachi Industries Ltd. in Dahej, Gujarat, Sweetener are purchased from Gujarat, India. Ondansetron purchased form Mercury Industries Ankleshwar, Gujarat (India) and magnesium stearate from Sunshine private limited, India and other chemicals used AR grades ${ }^{21}$.

\section{METHOD:}

\section{Preparation of BARETab® ODT}

It is a combination of binder/filler, glidant, sweeter and super disintegrant and by using coprocess technology. Co-processed make product with innovative properties. BARETab ${ }^{\circledR}$ ODT quick dissolving matrix design shown in figure $1^{22}$.

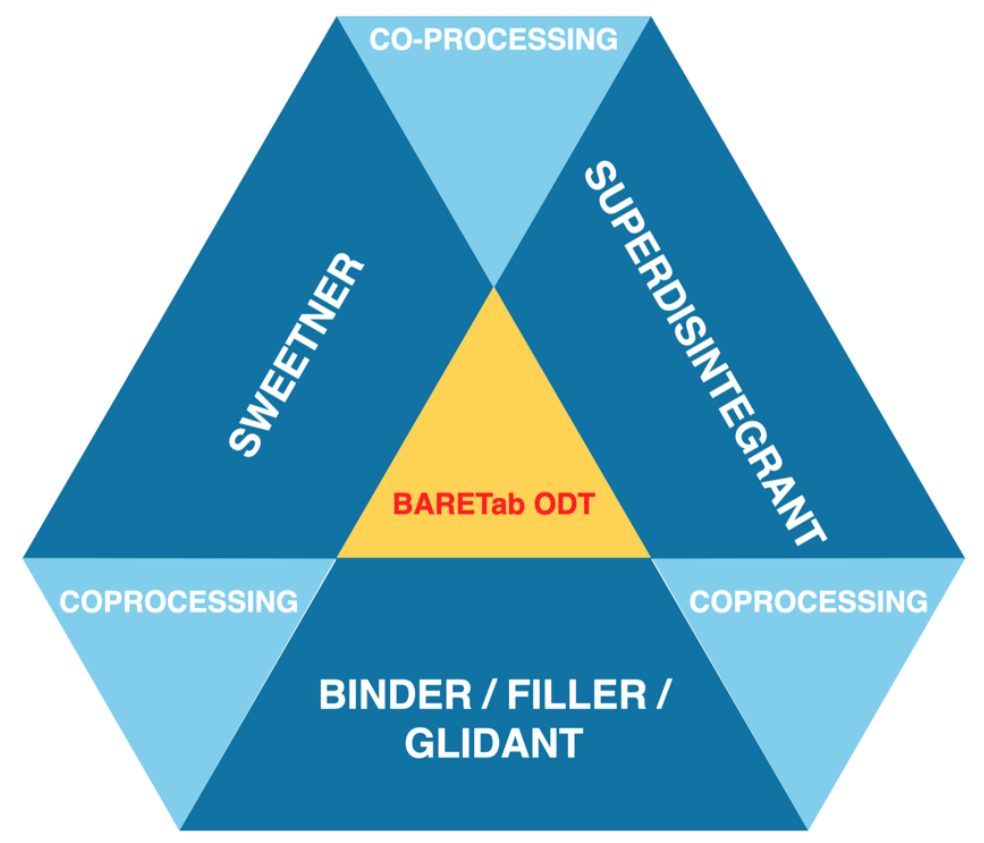

Figure 1: BARETab® ODT Design

\section{Characterization of BARETab ${ }^{\circledR}$ ODT}

\section{Fourier-transform infrared spectroscopy}

Make a mixer of BARETab ${ }^{\circledR}$ ODT and KBR in 3:1 ratio and make a homogenous mixer in mortar and pastel. Take sample in IR sample cup and placed the sample cup into sample compartment in IR, run the sample in IR $;^{23}$.

\section{Melting Point}

Take BARETab ${ }^{\circledR}$ ODT sample into a glass capillary, and place the capillary in melting point apparatus (Viggo) and observed the sample, when sample starts to melt, note the temperature ${ }^{24}$.

\section{Morphological study}

\section{Scanning electron Microscopic}


Take approximate 1 to 2 milligram of sample and mounted on double sided taped on aluminum stabs. Placed stabs into sample compartment into microscope. Micrographs were taken at appropriate magnification and particles surface visualization detailed analyzed by scanning electron microscope at SICART university, Anand, Gujarat (India) ${ }^{25}$.

\section{Physicochemical Evaluation}

\section{Untapped density}

Untapped bulk density analysed by Scott volumeter. Weight empty cup, place it under the chute and $10 \mathrm{~g}$ of each sample is poured into funnel through volumeter, at a rate suitable to prevent clogging, until the cup overflows. Level the excess powder and weight the filled cup ${ }^{25}$

Untapped density $(\mathrm{g} / \mathrm{ml})=\frac{\text { Sample Mass }(\mathrm{g})}{\text { Sample Volume }(\mathrm{ml})}$

\section{Tapped density}

Tapped density is determined by placing a graduated cylinder containing a known mass of final blend powder on a mechanical tapper apparatus (Model No. ETD 1020) which is operated at fixed number of tapped (500) until powder bed reached a minimum volume.

Tapped density $(\mathrm{g} / \mathrm{ml})=\frac{\text { Sample Mass }(\mathrm{g})}{\text { Sample Volume }(\mathrm{ml})}$

\section{Hausner's ratio}

It is indirect index for ease of measuring powder flow. Lower Hausner's ratio $(<1.25)$ indicates good flow property.

Hausner's Ratio $=\frac{\text { Tapped density }}{\text { Untapped density }}$

\section{Compressibility}

Compressibility known as carr's index. Based on the apparent bulk density and the tapped density. Percentage compressibility is calculated by below formula

Compressibility $(\%)=\frac{\text { Tapped density }- \text { bulk density }}{\text { Tapped density }} \times 100$

\section{Angle of repose}

Angle of repose is the angle obtained between freestanding surface of powder heap and the horizontal plane. It was determined by using the fixed funnel method. $20 \mathrm{gm}$ of final blend powder was poured into funnel keeping the orifice of the funnel blocked by thumb. When powder was cleared from funnel then the peak height was measured ${ }^{26}$.

\section{Particle size distribution analysis}

Particle size was analysed at Cubic Analytical Solution, Ankleshwar, Gujarat using lesser diffraction (Malvern instrument, Mastersizer v3.63). 


\section{Water content}

Water content analysed by using Karl Fischer (Viggo). Take 0.15 gm BARETab ODT sample and transfer in to the titration vessel containing previously neutralized methanol with Karl Fischer reagent. Dissolve the sample for about one minute and titrate the sample. Calculate water content using below formula ${ }^{27}$

Percentage of water content $(\mathrm{W} / \mathrm{V})=\frac{\text { Vol. of KF reagent consumed } \times \mathrm{KF} \text { Factor }\left(\frac{\mathrm{mg}}{\mathrm{ml}}\right) \times 100}{\text { Sample weight }(\mathrm{gm}) \times 1000}$

\section{Residue on ignition}

Heat a cleaned silica crucible to redness for 15 minutes in muffle furnace at $600{ }^{\circ} \mathrm{C} . \pm 50^{\circ} \mathrm{C}$ and allow to cool it in desiccators' and take the weight. Take 1 to 2 grams of sample into tarred crucible Moisten the sample with a small amount of sulphuric acid Heat it gently until the material is completely charred at a temperature as low as practicable, and ignite it at $600{ }^{\circ} \mathrm{C}$. $\pm 50^{\circ} \mathrm{C}$ for $3 \mathrm{hrs}$. Cool it in desiccators and weigh. Calculate the percentage of residue on ignition using below formula ${ }^{27}$

Residue on Ignition $(\%)=\frac{\text { Final weight }(\mathrm{gm})-\text { Tare weighgt }(\mathrm{gm})}{\text { Sample weight }(\mathrm{gm})} \times 100$

\section{Ondansetron blend Preparation}

Weigh accurately BARETab® ODT and Ondansetron using digital weighing balance (Mettler Toledo, ME303/A04), transfer both material into powder blender (Reva Pharma machinery, TRMIX-20) and blend the material for 5 minutes, after that added magnesium stearate for lubrication, lubricated the material for 3 minutes. Ondansetron blend is ready for tableting

Table 1: Ondansetron $4 \mathrm{mg}$ tablet manufacturing details

\begin{tabular}{ll}
\hline Ingredient Name & Quantity (W/W \%) \\
\hline Ondansetron & 16.67 \\
BARETab® ODT & 82.83 \\
Magnesium stearate & 0.50 \\
\hline
\end{tabular}

\section{Ondansetron Tablet compression}

$120 \mathrm{mg}$ tablets were manufactured by using 10 station Proton Mini Press (MINI PRESS 10 “D”) using D tooling dies and punches with $10 \mathrm{~mm}$ diameter, process of tableting shown in figure 2 . 

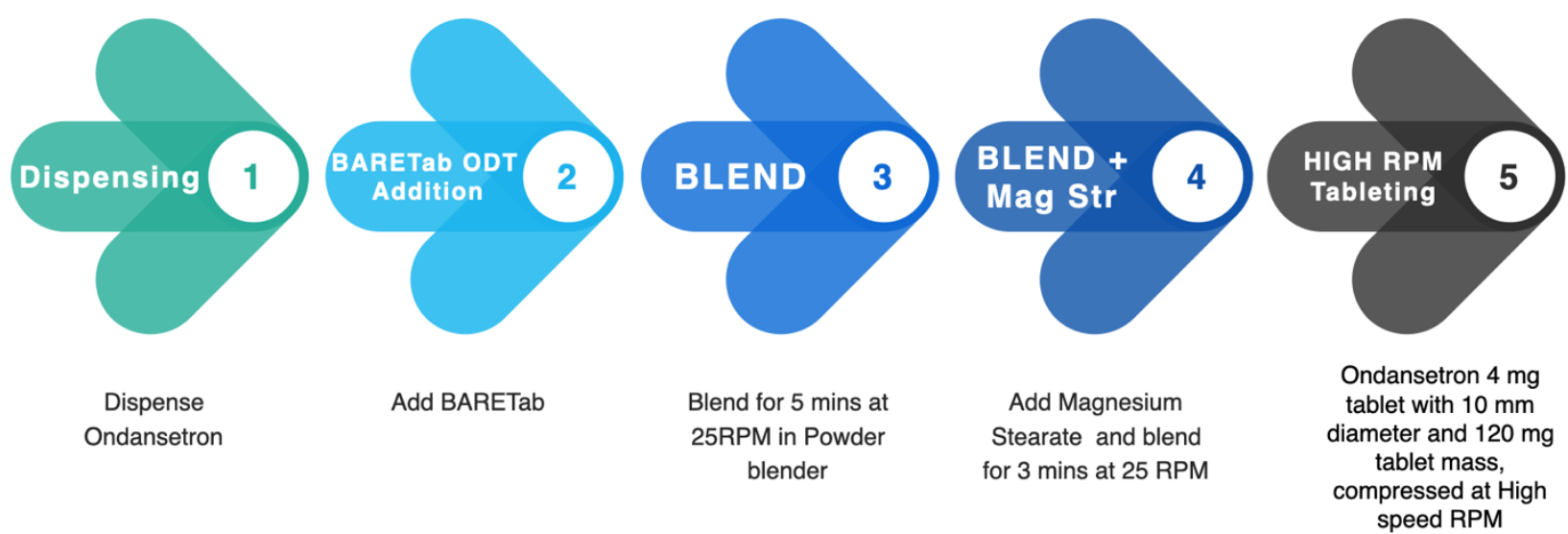

Figure 2: Ondansetron tablet preparation flow chart

\section{Physical appearance}

The general appearance Ondansetron tablet was studied visually in shape, colour, texture.

\section{Weight variation}

Weight variation test was performed by weighing 10 tablets individually using four-digit digital weighing balance (Mettler Toledo, MS304S/A01) and calculate the average weight ${ }^{28}$.

\section{Hardness}

Randomly 10 tablets were selected and analysed by electronic digital hardness test machine (TH1050 M). Single tablet was placed between two anvils, force was applied to the anvils, and the tensile strength that was just required to break the tablet was recorded. Finally, the reading was noted in Newton ${ }^{28}$.

\section{Friability}

10 tablets were taken and weighed by using electronic digital balance which was considered as the initial weight. All the tablets were placed in the drum of friability tester (FT1020) and allowed rotate 100 times at $25 \mathrm{rpm}$. After 100 revolutions, 10 tablets were removed and reweighed which was considered as the final weight. The percentage friability was calculated by below mention formula. As per USP, the tablets should not lose more than $1 \%$ of their total weight $^{29}$.

Percentage Friability $=\frac{\text { Initial weight }(\mathrm{gm})-\text { Final weight }(\mathrm{gm})}{\text { Inital weight }(\mathrm{gm})} \times 100$

\section{In vitro disintegration time}

Disintegration time of Ondansetron tablets were analysed by using tablet disintegration tester (Lab India, DT 1000) at $37 \pm 2^{\circ} \mathrm{C}$ in $800 \mathrm{ml}$ Demineralized water. Six tablets were taken and one tablet was introduced in each tube, disk was placed and basket was positioned in one litre beaker 
containing $37 \pm 2{ }^{\circ} \mathrm{C}$ temperature of water. Note down tablet breaking time. Noted the time when the tablet broke down into smaller particles ${ }^{31}$.

\section{In vitro dissolution profile}

Ondansetron released profile was analysed by using dissolution test apparatus (Lab India, DS 8000) and followed by USP method, apparatus type 2 (paddle), speed $50 \mathrm{rpm}$ in $500 \mathrm{ml}$ distilled water at $37 \pm 2{ }^{\circ} \mathrm{C}$ medium temperature. Randomly select 6 tablet and one tablet introduced in each beaker of dissolution. $5 \mathrm{ml}$ Sample were withdrawal from each beaker at different time intervals 5, 10, 15, 20, minutes. Samples filter with Whatman filter paper (42). Take $1 \mathrm{ml}$ sample from the beaker and transfer into $10 \mathrm{ml}$ of volumetric flask and makeup the volume up to the mark. Repeat the same procedure for all remaining 5 tablets containing samples. Take sample and standard absorbance using UV Spectrophotometer (Shimadzu model no-1900) at $\lambda=310 \mathrm{~nm}$ wavelength. Calculate ondansetron released profile with the help of below mention formula ${ }^{32}$ Amount of ondansetron released $(\mathrm{mg})=$

Conc.of released drug $\times$ dilution factor $\times$ Volume of dissolution medium 1000

Ondansetron released $(\%)=\frac{\text { Amount of ondansetron released }}{\text { Dose of ondansetron }} \times 100$

\section{RESULTS AND DISCUSSION:}

\section{Characterization of BARETab ${ }^{\circledR}$ ODT}

\section{Fourier-transform infrared spectroscopy}

Sweetener has properly coated on binder, filler, glidant and super-disintegrate and binder, glidant and super disintegrate peeks have shifted. BARETab ODT FT-IR graph shown in figure 3.

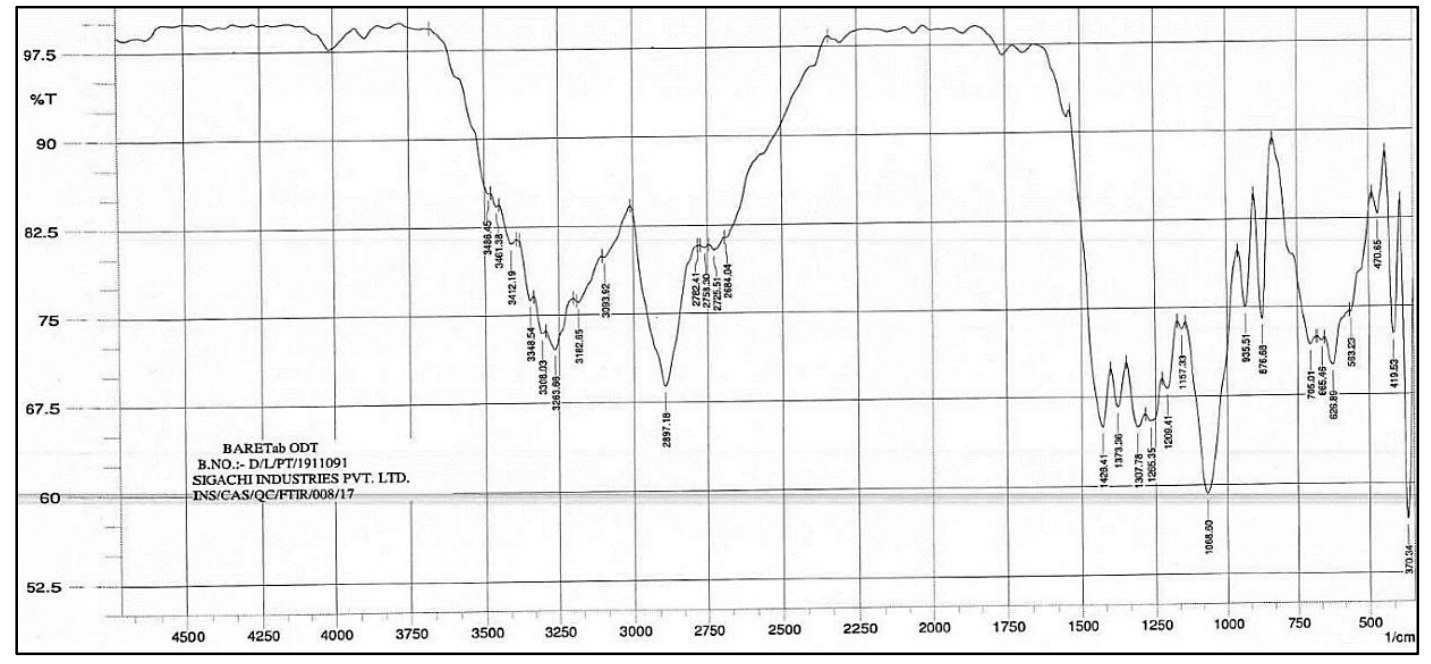

Figure 3: FTIR graph of BARETab® ODT 


\section{Melting point}

BARETab ${ }^{\circledR}$ ODT stared to melt between $162^{\circ} \mathrm{C}$ to $168^{\circ} \mathrm{C}$.

\section{Morphological study}

\section{Scanning electron Microscopic}

BARETab $^{\circledR}$ ODT single particle contains binder, filler, glidant, sweetener and disintegrant. Which gives homogenous mixing. SEM images shown in figure 4 binder, filler, glidant and disintegrant coated on every particles of mannitol. Which helped to made powder free flowing and good compressibility.

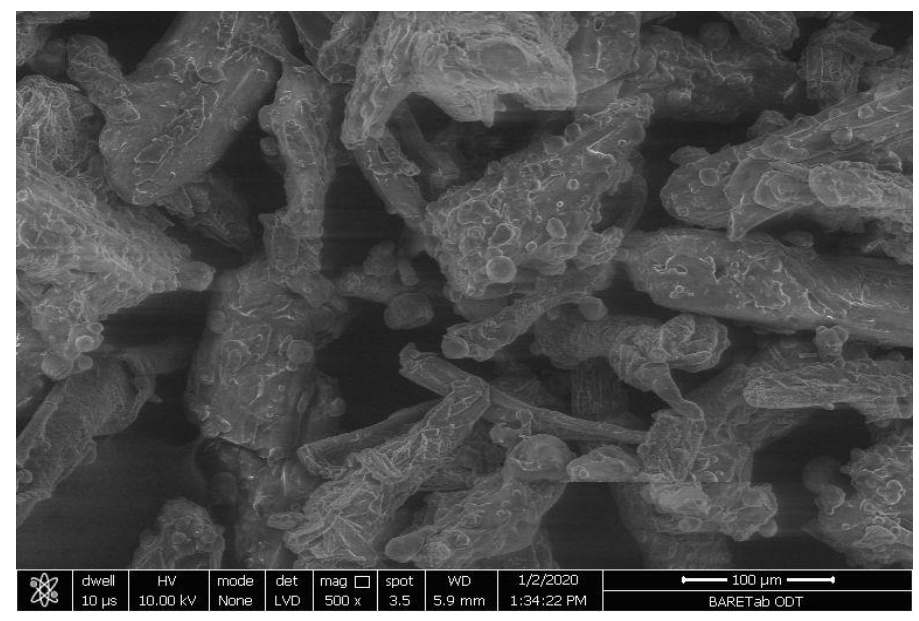

(a)

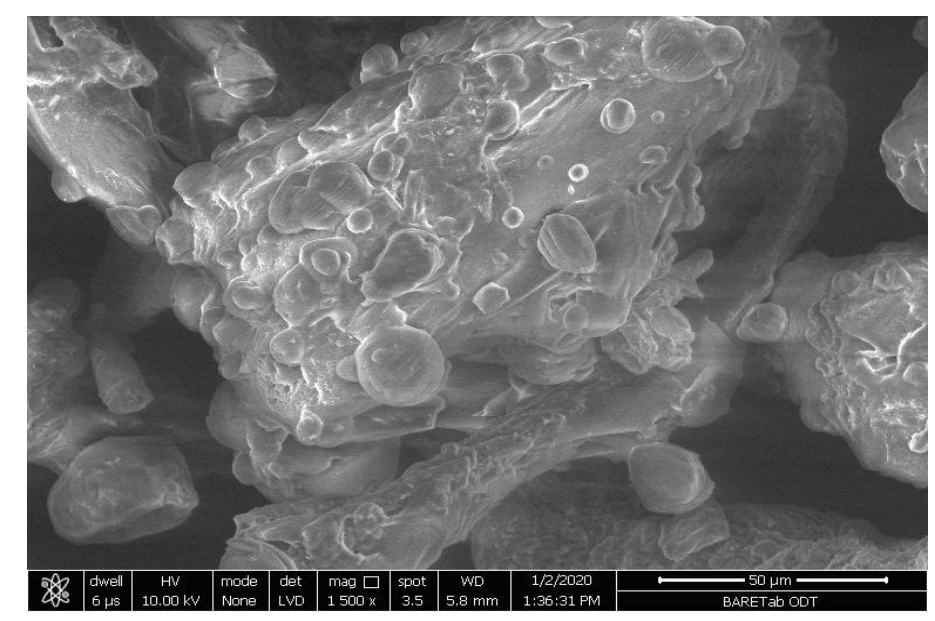

(b)

Figure 4 (a) \& (b): Scanning electron microscopic images of BARETab® ODT

\section{Physicochemical evaluation}

Physicochemical parameters are very important for final products, physical parameters help during tablet manufacturing, it controlled tablet rejection and helps to tablet machine run smoothly with high speed. Whereas chemical properties should be in limit, it controlled final 
product impurities. BARETab ${ }^{\circledR}$ ODT untapped density $0.41 . \mathrm{g} / \mathrm{cc}$ and tapped density $0.57 \mathrm{~g} / \mathrm{cc}$. higher bulk density improved flowability. Hausner's ratio and compressibility index are considered as indirect measurements of powder flowability, The Hausner's ratio is indicative of inter particle friction, while the Compressibility index shows the aptitude of a material to diminish in volume. As the values of these indices increase, the flow of the powder decrease. BARETab $^{\circledR}$ ODT has 1.3 Hausner's ratio and 28.4 compr4essibility index. The flow properties of powders are essential in determining the suitability of a material as a direct compression excipient. Increasing value is an indication of decreasing flowability. It has excellent flowability which is represented by angle of repose and it has $33^{\circ}$ angle of repose. Particle size play a very important role in direct compression formulation, it helps to carry equal API quantity in to the all tablets. BARETab ${ }^{\circledR}$ ODT average particle size is $98 \mu \mathrm{m}$. Water content analysed by Karl Fischer and found $1.0 \%$. Less water content prevents micro and helps to maintain stability. Residue on ignition analysed by muffle furnace and found $0.90 \%$.

\section{Tablet compression}

Ondansetron tablet punched at $320 \mathrm{KN}$ released pressured at high speed rpm, with Ondansetron machine run smoothly and gave more output.

\section{Ondansetron Tablet Evaluation}

Tablets are elongated shape and white color, odourless, sweet in taste and good mouth feel with smooth surface and free form all defects like capping, sticking, lamination and weight variation. All tablets have weight uniformity and tablet hardness has $320 \mathrm{~N}$. There is no loss have observed during friability test and found very less disintegration time 6.5 seconds whereas ODT disintegration time limit is below 30 seconds. Ondansetron released profile mentioned in figure: 5, wherein more than $80 \%$ drug released in 15 minutes.

Table 2: Orally disintegrating Ondansetron Tablet evaluation

\begin{tabular}{ll}
\hline Characteristics & Result \\
\hline Tablet appearance & Elongated, white color tablet \\
Taste & Sweet in taste with good mouth feel \\
Average tablet weight $(\mathrm{mg})$ & $120.0 \mathrm{mg}$ \\
Average hardness $(\mathrm{N})$ & $320.0 \mathrm{~N}$ \\
Friability (\%) & $00.0 \%$ \\
Average disintegration time $(\mathrm{Sec})$ & $6.5 \mathrm{~seconds}$ \\
\hline
\end{tabular}




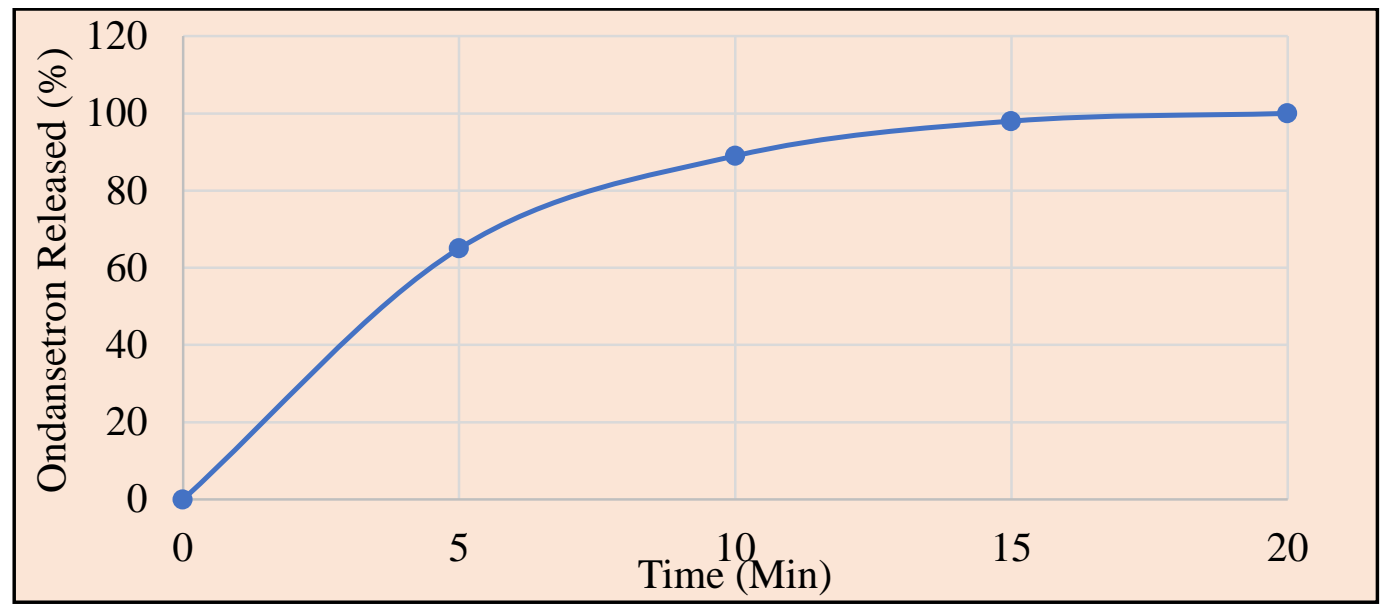

Figure 5: Ondansetron released profile

\section{CONCLUSION:}

This study concluded that BARETab ${ }^{\circledR}$ ODT quick dissolving matrix has multifunctional premix for ODT tablet, its each and every particle contains binder, filler, glidant, sweetener and superdisintegrant, which is proved by SEM and FTIR test, Super-disintegrant, binder, filler and glidant peeks have shifted due to coating. All material is coated to each other. It has outstanding flowability which helped during tablet manufacturing. Ondansetron tablets have good tablet taste with excellent mouth feel and have good tablet hardness and very less disintegration time. Its tablet disintegrated in 6. 5 seconds and ondansetron amount more than $80 \%$ released in 10 minutes.

\section{ACKNOWLEDGEMENT:}

The authors are thankful to Sophisticated Instrumentation Centre for Applied Research and Testing, (SICART), Gujarat, India for providing SEM testing facility.

\section{CONFLICTS OF INTERESTS:}

The authors state and confirm no conflict of interests. No direct funding was received for this study.

\section{REFERENCE:}

1. Armin H. Gerhardt. Moisture Effects on Solid Dosage Forms Formulation, Processing, and Stability. J of GXP Compliance 2009; 13:58-66.

2. Tomar M, Sinha AR, Singh AK. Process and development of co-processed excipient Silicified Microcrystalline Cellulose and manufacture Paracetamol tablet by direct compression. Int. J of Pharmaceutical Sciences review and Res 2017; 32:191-196. 
3. Chaudhary HN, Kumbhar S M, Dighe AD, Sapkal PA, Singh CM. Orally disintegrating drug delivery systems. J of Pharmacy Res 2012; 7:3791-3799.

4. Seager H. Drug delivery products and the zydis fast dissolving dosage form. J. Pharm. Pharmacol 1998; 50: 375-382.

5. Velmurugan S and Sundar Vinushitha. Oral Disintegrating Tablets: An Overview. Int. J of Chem and Pharma Sciences 2010;1: 1-12.

6. Lindgren S, Janzon L, Dysphagia. Prevalence of swallowing complaints and clinical findings. Medical clinics of North America 1993; 77: 3-5.

7. Hoda Tayebi and Seyed Alireza Mortazavi. Formulation and Evaluation of a Novel Matrix-Type Orally Disintegrating Ibuprofen Tablet. Iran J of Res 2011; 10:469-479.

8. Takagi H, Kajiyama A, Yanagisawa M. Rapidly disintegrable Pharmaceutical composition. US Patent 2005; 6: 899.

9. Kuchekar SB, Badhan CA, Mahajan SH. Pharma Times 2003; 35: 7.

10. Dobetti L. Fast Melting Tablets: development and technologies. Pharmaceutical Technology 2001; 44-50.

11. Van Scoik KG. Solid pharmaceutical dosage in tablet triturates form and method of producing the same. US patent. 2005; 082:667.

12. Makino T, Yamada M, Kikuta J. US patent 1998; 5: 20-34.

13. Gohel M, Patel M, Agarwal R, Dev R. Formulation design and optimization of mouth dissolve tablets of Nimesulide using vacuum drying technique. AAPS Pharm Sci Tech 2004;3: 36-45.

14. Abdelbary G, Prinderre P, Eouani C, Joachim J, Reynier JP, Piccerelle P. The preparation of orally disintegrating tablets using a hydrophilic waxy binder, Int. J of Pharmaceutics 2004; 278: 423-433.

15. Kuno Y, Kojima M, Ando S, Nakagami H. Evaluation of rapidly disintegrating tablets manufactured by phase transition of sugar alcohols. J of Control Release 2005; 105: 1622.

16. Gohel M, Patel M, Amin A, Agarwal R, Dave R, Bariya N. Formulation design and optimization of mouth dissolving tablets of Nimusulide using vaccum drying technique. AAPS Pharm Sci Tech 2004; 5: 1-6.

17. Panigrahi D, Baghel S, Mishra B. Mouth dissolving tablets: An overview of preparation techniques: Evaluation and patented technologies. J Pharm Research 2005; 4: 33-41. 
18. O’Connor R, Schwartz J. Extrusion, spheronization technology. In Pharmaceutical Pelletization technology. Marcel Dekker Inc. New York 1989; 37-187.

19. Agarwal V, Kothari B H, Moe D V, Khankari R K. Drug delivery: Fast dissolve system. In: Swarbrick J, Encyclopedia of pharm tech. New York, USA: Informa Healthcare Inc 2006; 1104-1114.

20. Masters K, Spray Drying Fundamentals: Process stages and layouts. In: Spray Drying Handbook. USA: Longman Scientific and Technical, New York, 5th ed. 1991; 23-64.

21. Gorle Ashish Prakash, Ritesh Rajput Bhagavansing. Formulation and development of taste masking orally dispersible Paracetamol tablet. J of Drug Delivery \& Therapeutics 2016; 6:30-36.

22. Kannuri R, Chamarthi H, Kumar Senthil M, Challa T, Agiah GB. Formulation development and in-vitro evaluation of Escitalopram Oxalate orally disintegrating tablet. Int. J of Pharmaceutical, Chem and biological sciences 2011; 1:57-65.

23. Ashok K, Ramaswamy. Phytochemical screening by FT-IR Spectroscopic analysis of leaf extracts of selected India medical plants. Int. J current microbiology applied sciences 2014;3:395-406.

24. United states pharmacopeia. General chapter, volume 40-NF 35, 2018.

25. Donovan N, Leonard Gary W, Chandler S.S. Characterization of Materials, second edition. Wiley online library2012; https://doi.org/10.1002/0471266965.com081.pub2.

26. United states pharmacopeia. General chapter: Bulk density. Volume 40-NF 35,2018.

27. United states pharmacopeia. General chapter: Powder flowability. Volume 40 (1) NF 35 (2018).

28. Aridizzone S, Francesco S.D, Patrizia Raman M, Mussini T. Microcrystalline cellulose powder structure, surface features and water sorption capabilities. Int. J of Biological Macromolecules 1999; 26: 269-277.

29. Monika T, Amit R.S, Ajay K. Process and development of co-processed excipient Silicified Microcrystalline Cellulose and manufacture Paracetamol tablet by direct compression. Int. J of Pharm Sciences review and research 2017;32 :191-196.

30. Nagar P, Singh K, Chauhan I, Verma M, Yasir M, Khan A, Sharma R, Gupta N. Orally disintegrating tablet: formulation, preparation techniques and evaluation 2011;1:35-45.

31. Bin KL, Anand G, Mandal UK. A review on co-processed excipient: current and future trend of excipient technology 2019;11: 1-9. 
32. Dong Y, Kulkarni R, Behme R.J, Kotiyan P.N. Effect of the melt granulation technique on the dissolution characteristics of Griseofulvin. Int. J. Pharm 2007; 72-80.

AJPHR is

Peer-reviewed monthly

Rapid publication

Submit your next manuscript at editor@ajphr.com / editor.ajphr@gmail.com 